BENTUK PERTUNJUKAN GURITAN PADA TRADISI PERNIKAHAN DI KOTA PAGARALAM

DedyFirduansyah, AbiKaroma Batubara

EKSISTENSI MUSIK KOLINTANG KAYU DALAM KEHIDUPAN PIKPP DI PT.PURSI PALEMBANG SUMATERA SELATAN

RIO EKA PUTRA

ESTETIKA TARI MELAJU DENGAN MUTU

Rully Rochayati, Treny Hera

KAJIAN SOSIOLOGI TARI KEBAGH DI MASYARAKAT DESA PENGANDONANKOTA PAGAR ALAMRANI CHINTIA SARI

KONTRIBUSI GURU SENI BUDAYA DALAM PENGEMBANGAN KREATIFITAS SISWA PADA PEMBELAJARAN SENI TARI

Naomi Diah Budi Setyaningrum

45

PENERAPAN METODE RESITASI DALAM PEMBELAJARAN NOTASI TARI PADA PROGRAM STUDI PENDIDIKAN SENDRATASIK UNIVERSITAS PGRI PALEMBANG

EfitaElvandari

PENGARUH METODE KERJA KELOMPOK PADA HASIL PEMBELAJARAN TARI TOPENG IRENG DI KELAS VIII SMP NEGERI 15 PALEMBANG

NEMI KAROLINA

PENGARUH MUSIK DANGDUTTERHADAP KECERDASAN EMOSI REMAJA SMPKELAS IX

NOVDALY FILLAMENTA

SITI RAFIAH SEBAGAI TOKOH PEREMPUAN PENGEMBAN PERISTIWA DALAM SYAIR ABDUL MULUK KARYA RAJA ALI HAJI

MOHAMMAD ARFANI

STRUKTUR KERUANGAN TARI REJANG RENTENG DALAM UPACARA PERSEMBAHYANGAN DI PURA PUSEH DESA KALIREJO KECAMATAN BELITANG II KABUPATEN OKU TIMUR

IWAYAN AYUNITA 


\title{
PENGARUH METODE KERJA KELOMPOK PADA HASIL PEMBELAJARAN TARI TOPENG IRENG DI KELAS VIII SMP NEGERI 15 PALEMBANG
}

\author{
Oleh: \\ Nemi Karolina \\ (Guru Seni Budaya Di MTS AI Mujahidin Kabupaten Musi Rawas)
}

\begin{abstract}
ABSTRAK
Penelitian ini dilatar belakangi oleh siswa di SMP Negeri 15 Palembang masih kurangnya minat siswa terhadap pembelajaran seni budaya, susah untuk menghafal gerak, dan kurangnya kerja sama antar individu.Penelitian ini bertujuan untuk mengetahui pengaruh penerapan metode kerja kelompok terhadap hasil belajar tari topeng ireng di kelas VIII SMP Negerii 15 Palembang. Metode dalam penelitian ini adalah kuantitatif eksperimen.Instrumen yang digunakan dalam penelitian ini adalah tes dan. Populasi dalam penelitian ini adalah kelas VIII di SMP Negeri 15 Palembang tahun pelajaran 2018/2019 dengan jumlah populasi sebanyak 287 siswa, sedangkan sampel diambil dengan penarikan sampel random sampling, sehingga sampel berjumlah 1 kelas atau sebanyak 31 siswa. Analisis data penelitian ini menggunakan uji normalitas data dan uji hipotesis data dari hasil analisis tersebut di peroleh thitung $=3,487$ lebih besar dari $t_{0,05}$ harga $t_{\text {tabel }}=1,70$ maka dari itu bahwa hipotesis yang diterima adalah $\mathrm{Ho}$ ditolak dan $\mathrm{Ha}$ diterima atau $\mathrm{t}_{\text {hitung }} \geq \mathrm{t}_{\text {tabel }}(3,487 \geq 1,70)$ dari hasil tersebut dinyatakan adanya pengaruh yang signifikan dalam pembelajaran gerak tari topeng ireng dengan menggunakan metode kerja kelompok dari kelas VIII SMP Negeri 15 Palembang.
\end{abstract}

Kata kunci : Metode Kerja Kelompok, Tari Topeng Ireng.

\section{A. PENDAHULUAN}

Latar belakang masalah atau latar belakang penelitian merupakan permasalahan didalam suatu penelitian yang perlu dicarikan solusinya.Latar belakang adalah suatu kumpulan informasi yang disusun secara sktruktur dan sistematis, dimana berhubungan dengan permasalahan yang sedang dihadapi oleh peneliti.

Menurut Purwanto (2014:24), Pendidikan merupakan usaha sadar yang dilakukan oleh individu/kelompok tertentu melalui kegiatan pengajaran atau pelatihan, yang berlangsung sepanjang hidup diberbagai lingkungan belajar dalam rangka mempersiapkan manusia agar dapat memainkan peran secara tepat. Unsur-unsur yang harus ada dalam pendidikan yaitu: Peserta didik, pendidik, interaktif edukatif, tujuan pendidikan, materi pendidikan, metode pendidikan, dan lingkungan pendidikan. Berdasarkankonsepsi-konsepsi pendidikan pada dasarnya upaya-upaya (proses) di dalam pendidikan pada 
akhirnya menampakkan diri dari dalam, terwujudnya pribadi yang sesuai dengan kenyataan diri dan lingkungan seseorang. Demikian, pada hakikatnya pendidikan adalah upaya memanusiakan manusia, dan membudayakan manusia, sehingga mampu mencipta, berkarya, berbudi baik diri bagi kehidupan ekosferisnya kebulatan diri dan lingkungan.

Selain itu pendidikan pasti adanya proses belajar pembelajaran, menurut Slameto dalam Hamdani (2011:20), "Pengertian belajar adalah suatu proses usaha yang dilakukan seseorang untuk memperoleh perubahan tingkah laku yang baru secara keseluruhan, sebagai hasil pengalamannya sendiri dalam interaksi dengan lingkungannya". Sedangkan menurut Hamdani (2011: 72-80) "pembelajaran ( belajar dan mengajar ) merupakan proses komunikasi antara guru dan siswa. Komunikan pada proses pembelajaran adalah siswa, sedangkan komunikatornya adalah guru dan siswa. Dalam proses pembelajaran pasti menggunakan metode pembelajaran, metode pembelajaran itu adalah cara yang digunakan guru untuk menyampaikan pelajaran kepada siswa".
Berdasarkan observasi awal, serta informasi dari guru seni budaya ibu Novi Agustina S.Pd di SMP Negeri 15 Palembang, adanya fakta bahwa siswa di SMP Negeri 15 Palembang masih kurangnya minat siswa terhadap pembelajaran seni budaya, susah untuk menghafal gerak, dan kurangnya kerja sama antar individu. Untuk mengatasi permasalahan tersebut, peneliti bermaksud untuk mengadakan penelitian di SMP Negeri 15 Palembang dengan menggunakan metode baru.

Metode yang digunakan dalam penelitian ini adalah metode kerja kelompok.Teknik ini sebagai salah satu strategi belajar mengajar. Kerja kelompok ialah suatu cara mengajar, dimana siswa di dalam kelas dipandang sebagai suatu kelompok atau dibagi menjadi beberapa kelompok. Setiap kelompok terdiri dari 5 (lima) atau 7 (tujuh) siswa, mereka bekerja bersama dalam memecahkan masalah, atau melaksanakan tugas tertentu, dan berusaha mencapai tujuan pengajaran yang telah ditentukan pula oleh guru, menurut Martin dalam Roestiyah (2012:15). Memberikan pengertian kerja kelompok sebagai kegiatan sekelompok siswa yang biasanya berjumlah kecil, 
yang diorganisir untuk kepentingan belajar.Keberhasilan kerja kelompok ini menuntut kegiatan yang kooperatif dari beberapa individu tersebut. Penggunaan teknik kerja kelompok untuk mengajar mempunyai tujuan agar siswa mampu bekerja sama dengan teman yang lain dalam mencapai tujuan bersama.

\section{B. METODE PENELITIAN}

Menurut Arikunto (2014:203), "Metode penelitian adalah cara yang digunakan oleh peneliti dalam mengumpulkan data penelitiannya."

Berdasarkan pengertian tersebut metode yang digunakan peneliti pada penelitian adalah metode kuantitatif, yaitu eksperimen yang didasarkan pada perhitungan statistik yaitu mengukur pengaruh dari pemberian metode kerja kelompok pada pembelajaran tari Topeng Ireng di kelas VIII SMP Negeri 15 Palembang.

Pada penelitian yang dilakukan, peneliti menggunakan pre-Expremental Designs yaitu One-Grouppretest-posttest Designs merupakan desain yang terdapat pretes (sebelum diberi perlakuan). Alasan mengapa menggunakan Pre-Expremental Designs karena dapat melihat atau mengetahui
Dalam penelitian ini, peneliti melakukan penelitian di SMP Negeri 15 Palembang, dengan kurikulum yang digunakan sekolah adalah kurikulum 2013. Pada proses pembelajaran, guru telah mempersiapkan RPP supaya pelaksanaan proses pembelajaran berjalan dengan baik.

perbandingan antara nilai sebelum dilakukan (pretest) dan nilai sesudah dilakukan (posttest), sehingga peneliti dapat mengetahui pengaruh metode Kerja Kelompok yang digunakan dalam pembelajaran tari Topeng Ireng. Dengan demikian perlakuan dapat diketahui lebih akurat, karena dapat membandingkan dengan keadaan sebelum diberi perlakuan. Desain ini dapat digambarkan sebagai berikut:

\section{$01 \times 02$}

Keterangan:

01 :Pretest (Sebelum diberi perlakuan)

$X$ : Perlakuan

O2 :Posttest (Sesudah diberi perlakuan)

Dalam penelitian ini hanya ada satu kelas yang menjadi kelas eksperimen yang dilakukan tanpa ada 
kelas pembanding (kelas kontrol), dimana penelitian bertujuan untuk

\section{C.HASIL DAN PEMBAHASAN}

Pelaksanaan penelitian dilakukan pada saat bulan suci Ramadhan. Melihat situasi dan kondisi di SMP Negeri 15 Palembang terdapat kelas yang berjumlah 12 ruang kelas itu sudah termasuk prasarana, dan terdapat 9 ruang wc disekolah tersebut, prasarana lainnya terdapat 1 ruang tersendiri tetapi yang belum ada di SMP Negeri 15 Palembang tersebut ruang seni apa lagi untuk ruang seni tari belum ada. Pegawai tenaga kerja ( guru ) terdapat 53 orang tenaga kerja, dan peserta didik total keseluruhannya yaitu berjumlah 798 orang siswa yang terdiri dari 350 orang siswa laki-laki, 448 orang siswi perempuan. Peneliti melakukan penelitian pertemuan pertama pada hari selasa tanggal 14 Mei 2019, pertemuan kedua pada hari kamis 16 Mei 2019, dan pertemuan ketiga pada hari selasa 21 Mei 2019. Peneliti melakukan penelitian dengan mengambil jam pelajaran guru seni budaya yaitu ibu Novi Agustina, selama 2 minggu dikarenakan bulan suci Ramadhan dan dipercepat karena minggu-minggu terakhir siswa libur. Penelitian ini berjudul " Pengaruh Metode menerapkan suatu tindakan atau perlakuan agar hasil lebih optimal. Kerja Kelompok Pada Pembelajaran Tari Topeng Ireng Di Kelas VIII SMP Negeri 15 Palembang Tahun Ajaran 20182019". Tujuan dari penelitian ini untuk mengetahui adakah pengaruh metode kerja kelompok pada pembelajaran tari Topeng Ireng di kelas VIII SMP Negeri 15 Palembang.

Penelitian ini telah dilakukan dengan tiga tahapan, yaitu tahap perencanaan, tahap pelaksanaan dan tahap pelaporan. Pada tahap perencanaan peneliti sudah mendapat surat pengantar untuk melaksanakan penelitian dari Fakultas Keguruan dan IImu Pendidikan Universitas PGRI Palembang. Selanjutnya peneliti mengurus surat izin penelitian ke diknas pendidikan kota Palembang Jl. Srijaya KM 5,5 dan selanjutnya surat izin tersebut diserahkan ke Sekolah SMP Negeri 15 Palembang sebagai objek penelitian.

Hasil observasi yang telah dilakukan, didapat populasi pada penelitian ini yang secara keseluruhan terdiri dari 9 kelas dengan jumlah keseluruhan siswa terdapat 287 siswa putra dan putri dengan sampel penelitian 
kelas VIII 5 sebagai kelas eksperimen yang berjumlah 31 siswa, yang didapat menggunakan teknik random sampling yaitu dipilih secara acak dan semua siswa itu sama atau setrata atau setara. Berdasarkan penelitian yang telah dilakukan, didapat hasil nilai pembelajaran tari Topeng Ireng melalui pre-test yang dilaksanakan setelah sekali pertemuan selanjutnya dilakukan pembelajaran dua kali pertemuan dengan menerapkan metode kerja kelompok.Proses penelitian dilakukan dengan 3 tahap yaitu persiapan, pelaksanaan, dan penilaian. Hasil dari penelitian ini dapat dilihat pada tabel dibawah ini.

\section{Pertemuan Pertama}

peneliti membuka pembelajaran dengan salam dan mengabsensi siswa, peneliti menjelaskan tujuan pembelajaran tari Topeng Ireng dan memberikan manfaatnya sehingga siswa dan siswi siap untuk belajar. Mulai menjelaskan pengertian dan asal usul tari topeng ireng, fungsinya, gerak tari dan maupun perubahan yang terjadi pada tari Topeng ireng sebagai pembelajaran sesuai kebutuhan akademik.Lalu mengajarkan gerakan tari tersebut kepada siswa dan melakukan penilaian pre-test terhadap siswa sebelum menyelesaikan pembelajaran siswa dibagi kelompok.

\section{Pertemuan Kedua}

Peneliti menerapkan metode kerja kelompok, lalu melanjutkan pembelajaran mengenai gerak tari Topeng Ireng secara berkelompok sesuai kelompok masing-masing yang sudah dibagikan.Tidak hanya itu diikuti dengan mengingat sedikit tentang pengertian tari tersebut, Lanjut dilakukan praktik berkelompok.

\section{Pertemuan Ketiga}

peneliti melakukan post-test terhadap siswa secara perkelompok sesuai dengan metode yang digunakan.

\section{Hasil dan Analisis Data Tes}

Tes ini dilakukan untuk mengetahui hasil belajar siswa yang diambil nilai tes unjuk kerja yaitu pre-test dan post-test pada pembelajaran tari Topeng Ireng yang diajarkan dengan menggunakan metode kerja kelompok

\section{Analisis Data Pre-test Pembelajaran} Tari Topeng Ireng

Hasil Pre-test yang diperoleh
siswa pada hasil pembelajaran tari
Topeng Ireng.


TABEL DISTRIBUSI FREKUENSI NILAI PRE-TEST

\begin{tabular}{|c|c|c|c|c|c|}
\hline $\begin{array}{l}\text { Nilai Ujian } \\
\text { (Interval) }\end{array}$ & $\mathrm{Fi}$ & $\mathrm{Xi}$ & $\mathrm{Xi2}$ & $\mathrm{Fi} . \mathrm{Xi}$ & $\mathrm{Fi} . \mathrm{Xi2}$ \\
\hline $55-59$ & 4 & $(55+59 \div 2)=57$ & 3,249 & 228 & 12,996 \\
\hline $61-65$ & 5 & 63 & 3,969 & 315 & 19,845 \\
\hline $66-70$ & 8 & 68 & 4,624 & 544 & 36,992 \\
\hline $71-75$ & 9 & 73 & 5,329 & 675 & 47,961 \\
\hline $76-80$ & 4 & 78 & 6,084 & 312 & 24,336 \\
\hline $81-85$ & 1 & 83 & 6,889 & 83 & 6,889 \\
\hline & 31 & 422 & 30,144 & 2,139 & 149,019 \\
\hline
\end{tabular}

3. Mencari Simpangan Baku

1. Mencari Rata-Rata Dengan

$$
\mathrm{S}^{2}=
$$

\section{Rumus:}

$$
\begin{aligned}
\bar{x} & =\frac{\sum f i x i}{\Sigma f i} \\
& =\frac{}{} \\
& =69
\end{aligned}
$$

2. Mencari Modus Dengan

$$
\begin{array}{r}
\frac{n \sum f_{i} \cdot x_{i}{ }^{2}-\left(\sum f_{i} \cdot x_{i}\right)^{2}}{n(n-1)} \\
=\frac{31(149,019)-(2,139)}{31(31-1)} \\
=\frac{4619,589-4575,321}{930}
\end{array}
$$

Rumus:

$$
M o=b+p\left[\frac{b_{1}}{b_{1}+b_{2}}\right]
$$

$$
=\overline{47,6}
$$

kelas modus $=$ kelas ke 4

$$
\begin{array}{cc}
\mathrm{b} & =70,5 \\
\mathrm{~b} 1 & =9-8=1 \\
\mathrm{~b} 2 & =9-4=5 \\
\mathrm{P} & =5 \\
M o= & 70,5+5\left[\frac{1}{1+5}\right] \\
= & 71,33
\end{array}
$$

\section{Analisis Data Post-test Pembelajaran Tari Topeng Ireng} Hasil Post-test yang diperoleh siswa pada hasil pembelajaran tari Topeng Ireng sesudah diterapkan metode kerja kelompok, dapat dilihat pada tabel distribusi frekuensi berikut ini 
TABEL DISTRIBUSI FREKUENSI NILAI POST-TEST

\begin{tabular}{|c|c|c|c|c|c|}
\hline $\begin{array}{l}\text { Nilai Ujian } \\
\text { (Interval) }\end{array}$ & Fi & Xi & Xi2 & Fi . Xi & Fi . Xi2 \\
\hline $68-72$ & 4 & $(68+72 \div 2)=70$ & 4,900 & 280 & 19,600 \\
\hline $73-77$ & 8 & 75 & 5,625 & 600 & 45,000 \\
\hline $78-82$ & 9 & 80 & 6,400 & 640 & 51,200 \\
\hline $83-87$ & 7 & 85 & 7,225 & 595 & 50,575 \\
\hline $88-92$ & 3 & 90 & 8,100 & 270 & 24,300 \\
\hline $93-97$ & 1 & 95 & 9,025 & 95 & 69,025 \\
\hline & 31 & 495 & 41,275 & 2,481 & 199,700 \\
\hline & & & \multicolumn{3}{r}{$M o=77,5+5\left[\frac{1}{1+2}\right]$} \\
\end{tabular}

1. Mencari Rata-Rata Dengan

Rumus:

$$
\begin{aligned}
\bar{x} & =\frac{\sum f i x i}{\Sigma f i} \\
& = \\
& =80,03
\end{aligned}
$$

2. Mencari Modus Dengan

Rumus:

$$
\begin{aligned}
& M o=b+p\left[\frac{b_{1}}{b_{1}+b_{2}}\right] \\
& \text { kelas modus }=\text { kelas ke } 4 \\
& \text { b }=77,5 \\
& \text { b1 }=9-8=1 \\
& \text { b2 } \quad=9-7=2 \\
& \mathrm{P} \quad=5
\end{aligned}
$$

$$
=79,16
$$

3. Mencari Simpangan Baku

$$
\begin{array}{r}
\mathrm{S}^{2}=\frac{n \sum f_{i} \cdot x_{i}{ }^{2}-\left(\sum f_{i} \cdot x_{i}\right)^{2}}{n(n-1)} \\
=\frac{31(199,700)-(2,481)}{31(31-1)}
\end{array}
$$$$
=\frac{6190,700-6155,361}{930}
$$

$$
=\overline{35,339}
$$$$
=5,94
$$

\section{Uji Hipotesis Data}

Setelah pengujian

normalitas data didapat maka 
selanjutnya pengujian hipotesis penelitian dengan menggunakan statistik parameter yaitu uji t, dengan rumus sebagai berikut:

$$
\mathrm{t}=\frac{\mathrm{Md}}{\sqrt{\left(\frac{\sum \mathrm{x}^{2} d}{\mathrm{~N}(\mathrm{~N}-1)}\right)}}
$$

Dapat dilihat tabel uji t sebagai berikut :

TABEL 14

NILAI PREE-TEST DAN POST-TEST

\begin{tabular}{|c|c|c|c|c|}
\hline No & Nama Siswa & Nilai Pree-test & Nilai Post-test & $\begin{array}{l}\text { Gain (d). (Prost- } \\
\text { test Pree-test }\end{array}$ \\
\hline 1 & ASD & 60 & 79 & 19 \\
\hline 2 & AN & 63 & 74 & 11 \\
\hline 3 & $\mathrm{AP}$ & 74 & 85 & 11 \\
\hline 4 & $\mathrm{FC}$ & 62 & 95 & 33 \\
\hline 5 & FCP & 62 & 78 & 16 \\
\hline 6 & $\mathrm{FZ}$ & 79 & 75 & -4 \\
\hline 7 & $\mathrm{HA}$ & 55 & 78 & 23 \\
\hline 8 & LZ & 68 & 80 & 12 \\
\hline 9 & M. A & 75 & 85 & 10 \\
\hline 10 & M. AS & 73 & 84 & 11 \\
\hline 11 & M. E & 68 & 80 & 12 \\
\hline 12 & M. I & 74 & 73 & -1 \\
\hline 13 & M. R & 55 & 68 & 13 \\
\hline 14 & M. RG & 74 & 68 & -6 \\
\hline 15 & MA & 75 & 80 & 5 \\
\hline 16 & Moch. Z & 70 & 85 & 15 \\
\hline 17 & MF & 70 & 78 & 8 \\
\hline 18 & MuA & 56 & 74 & 18 \\
\hline 19 & NS & 66 & 84 & 18 \\
\hline
\end{tabular}




\begin{tabular}{|c|l|c|c|c|}
\hline 20 & NP & 84 & 79 & -5 \\
\hline 21 & NS & 68 & 90 & 22 \\
\hline 22 & NM & 79 & 68 & -11 \\
\hline 23 & PJ & 75 & 75 & 0 \\
\hline 24 & R. M & 79 & 89 & 10 \\
\hline 25 & RV & 68 & 68 & 0 \\
\hline 26 & RS & 55 & 90 & 35 \\
\hline 27 & SA & 79 & 75 & -4 \\
\hline 28 & SN & 74 & 85 & 11 \\
\hline 29 & SR & 67 & 80 & 13 \\
\hline 30 & S & 62 & 74 & 12 \\
\hline 31 & TAF & 74 & 85 & 11 \\
\hline & & 2,208 & 2,366 & $\sum \mathrm{d}=318$ \\
& & & & \\
\hline
\end{tabular}

Sebelum uji t, mencari nilai selisih rata$\mathrm{Md}=\underline{\Sigma}=-=10,25$

rata dengan menggunakan rumus:

Maka didapatlah Md yaitu 10, 25

TABEL 15

DEVIASI MASING-MASING NILAI

\begin{tabular}{|c|l|c|c|c|}
\hline No & \multicolumn{1}{|c|}{ Nama Siswa } & D & $(\mathrm{d}-\mathrm{Md})$ & \\
\hline 1 & ASD & 19 & 8,75 & 76,5625 \\
\hline 2 & AN & 11 & 0,75 & 0,5625 \\
\hline 3 & AP & 11 & 0,75 & 0,5625 \\
\hline 4 & FC & 33 & 22,75 & 517,5625 \\
\hline 5 & FCP & 16 & 5,75 & 33,0625 \\
\hline 6 & FZ & -4 & $-14,25$ & 203,0625 \\
\hline 7 & HA & 23 & 12,75 & 162,5625 \\
\hline
\end{tabular}




\begin{tabular}{|c|c|c|c|c|}
\hline 8 & LZ & 12 & 1,75 & 3,0625 \\
\hline 9 & M. A & 10 & $-0,25$ & 0,0625 \\
\hline 10 & M. AS & 11 & 0,75 & 0,5625 \\
\hline 11 & M. E & 12 & 1,75 & 3,0625 \\
\hline 12 & M. I & -1 & $-11,25$ & 126,5625 \\
\hline 13 & M. R & 13 & 2,75 & 7,5625 \\
\hline 14 & M. RG & -6 & $-16,25$ & 264,0625 \\
\hline 15 & MA & 5 & $-5,25$ & 27,5625 \\
\hline 16 & Moch. Z & 15 & 4,75 & 22,5625 \\
\hline 17 & MF & 8 & $-2,25$ & 5,0625 \\
\hline 18 & $\mathrm{MuA}$ & 18 & 7,75 & 60,0625 \\
\hline 19 & NS & 18 & 7,75 & 60,0625 \\
\hline 20 & $\mathrm{NP}$ & -5 & $-15,25$ & 232,5625 \\
\hline 21 & NS & 22 & 11,75 & 138,0625 \\
\hline 22 & NM & -11 & $-21,25$ & 451,5625 \\
\hline 23 & $\mathrm{PJ}$ & 0 & $-10,25$ & 105,0625 \\
\hline 24 & R. M & 10 & $-0,25$ & 0,0625 \\
\hline 25 & $\mathrm{RV}$ & 0 & $-10,25$ & 105,0625 \\
\hline 26 & RS & 35 & 24,75 & 612,5625 \\
\hline 27 & SA & -4 & $-14,25$ & 203,0625 \\
\hline 28 & SN & 11 & 0,75 & 0,5625 \\
\hline 29 & SR & 13 & 2,75 & 7,5625 \\
\hline 30 & $S$ & 12 & 1,75 & 3,0625 \\
\hline 31 & TAF & 11 & 0,75 & 0,5625 \\
\hline \multirow{2}{*}{\multicolumn{2}{|c|}{$\mathrm{N}=31$}} & 318 & & \\
\hline & & & & $\Sigma=3433,938$ \\
\hline
\end{tabular}


Setelah didapat selisih rata-rata, selanjutnya mencari jumlah kuadrat deviasi dapat dapat juga menggunakan rumus berikut:

$$
\begin{aligned}
& \sum d=\sum \underline{(\Sigma)} \\
= & 19+11+11+33+16+(-4)+23+12+10+11+12+ \\
& (-1)+13+(-6)+5+15+8+18+18+(-5)+22+ \\
& (-11)+0+10+0+35+(-4)+11+13+12+11- \\
& \\
= & 6,373- \\
= & 6,373-3262,06 \\
= & 3110,94 \\
= & 3111
\end{aligned}
$$

Kemudian dengan menggunakan rumus :

$$
\mathrm{t}=\frac{\mathrm{Md}}{\sqrt{\left(\frac{\sum \mathrm{x}^{2} d}{\mathrm{~N}(\mathrm{~N}-1)}\right)}}
$$
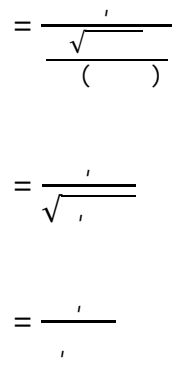

$=3.487$

Untuk mencari untuk t $(1-\mathrm{N})$ adalah :

d.b. $\quad=\mathrm{N}-1$

d.b. $\quad=31-1$ 


$$
\text { d.b. } \quad=30
$$

$$
\text { Dengan , hargat }=1,70
$$

Maka sesuai dengan pengujian hipotesis dapat disimpulkan pengujian hipotesis yaitu :

$$
\text { Ha jika maka Ho ditolak }
$$

Ho jika maka Ha ditolak

Hasil perhitungan diatas diperoleh $\quad=3,487$ lebih besar dari, harga $=$ 1,70. Maka dari itu bahwa hipotesis yang diterima adalah Ho ditolak dan Ha diterima atau $(3,487 \geq 1,70)$. Dari hasil diatas berarti adanya pengaruh yang signifikan dalam pembelajaran gerak tari Topeng Ireng dengan menggunakan metode kerja kelompok di kelas VIII SMP Negeri 15 Palembang.

\section{SIMPULAN}

Penelitian ini telah dilaksankan di SMP Negeri 15 Palembang, yang terletak di Jl.A. Yani 8 Ulu Kelurahan Sileberanti Kecamatan seberang ulu 1 Kota Palembang Propinsi Sumatera Selatan. Penelitian ini dilakukan selama tiga kali pertemuan di kelas VIII 5, pelaksanaan penelitian dilakukan pada saat bulan suci Ramadhan. Melihat situasi dan kondisi di SMP Negeri 15 Palembang proses pembelajaran yang berjalan dengan lancar.Berdasarkan hasil yang diperoleh peneliti dan dilakukan uji normalitas dan uji t sebagi pengujian hipotesis, dapat disimpulkan bahwa adanya pengaruh metode kerja kelompok pada hasil pembelajaran tari Topeng Ireng di kelas VIII SMP Negeri 15 Pale. Metode kerja kelompok dalam pembelajaran sangat efektif diterapkan disekolah terutama dalam materi pelajaran yang praktik, karena siswa dapat berlatih terusmenerus.Sehingga memperoleh ketangkasan ataupun keterampilan dalam bidang seni budaya khususnya seni tari. hasil yang didapat dengan menggunakan metode kerja kelompok yaitu baik, hal ini dapat dilihat dari perbandingan nilai terbesar pre-test 84 , nilai terendah pre-test 55 , dan hasil nilai rata-rata pree-test 70 sedangkan nilai terbesar post-test 95, dan nilai terendah post-test 68 dan hasil nilai rata-rata diperoleh post-test 80 . Dengan menggunakan uji $t$ hipotesis dengan atau $(3,487 \geq 1,70)$. Dari uji $t$ tersebut dapat dilihat adanya pengaruh metode kerja kelompok hasil belajar pada pembelajaran tari Topeng Ireng di kelas VIII SMP Negeri 15 Palembang. 


\section{DAFTAR PUSTAKA}

Anwar, Desi. 2002. Kamus Bahasa Indonesia Modern. Surabaya: Amelia

Arikunto, Suharsimi.2014. Prosedur Penelitian Suatu Pendekatan Praktik. Jakarta: Rineka Cipta.

Faradillah Desy, Treny Hera. 2016.Sitakara.Pengaruh Penerapan Metode Kerja Kelompok Terhadap Hasil Belajar Tari Tangga Pada Ssiswa Kelas VIII Di SMP.

Negeri 33 Palembang. Jurnal Pendidikan Seni Dan Seni Budaya. II (2), 40.

Hamdani, 2011. Strategi Belajar Mengajar. Bandung: Pustaka Setia.

Hapsari, Lisa. 2013. Fungsi Topeng Ireng Di Kurahan Kabupaten Magelang. Jurnal Pengetahuan dan Pemikiran Seni .13(2),139-140.

Huda, Miftahul. 2014. Model-Model Pengajaran dan Pembelajaran. Yogyakarta: Pustaka Pelajar.

Matondang, Zulkifli. 2009. Validitas Dan Reliabilitas Suatu Instrumen Penelitian.JurnalTabularasa PPS Unimed. 6(1),41.

Purwanto, Nanang. 2014. Pengantar Pendidikan. Yogyakarta: Graha IImu.

Roestiyah. 2012. Strategi Belajar Mengajar. Jakarta: Rineka Cipta.

Sudjana. 2005. Metode Statistika. Bandung : Tarsito.

Sugiyono. 2016. Metode Penelitian Kuantitatif, Kualitatif, dan R\&amp;D. Bandung: Alvabeta CV. 